\title{
Deceased Donor Donation Condition
}

National Cancer Institute

\section{Source}

National Cancer Institute. Deceased Donor Donation Condition. NCI Thesaurus. Code C139270.

The conditions under which an organ is harvested from a dead donor, including the condition of the donor and the environment. 